\title{
A Study Of Building An Intellectual Working Value Improvement Model "IWV-IM"
}

Masashi Tsunoi, Aoyama Gakuin University, Japan Manabu Yamaji, Waseda University, Japan

Kakuro Amasaka, Aoyama Gakuin University, Japan

\begin{abstract}
In order for Japan's manufacturing industry to succeed amidst today's global competition, companies must further increase the quality of tasks performed by on-site workers (worker dedication), thereby enabling them to create products with superior QCD. To this end, the authors investigated the problems currently facing manufacturing sites and identified their key factors. They then used these factors to formulate the Intellectual Working Value Improvement Model "IWV-IM" designed to improve working value and increase worker dedication. The effectiveness of this model was then verified.
\end{abstract}

Keywords: Manufacturing industry, working value, Toyota

\section{INTRODUCTION}

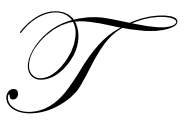

he environment surrounding Japan's manufacturing industry has undergone sweeping changes beyond those seen just a few years ago. Today's companies must offer products that customers find attractive as they strive to accurately grasp a wide range of consumer tastes. At the same time, one of the biggest management issues facing these companies is the need for a successful global production strategy that delivers high-quality products. These products must increasingly delight customers if the companies are to survive global quality competition in the manufacturing industry. Key to meeting this challenge is being able to create products with superior QCD, which requires improving the quality of tasks performed by on-site workers (worker dedication). In other words, boosting working value is more important than ever.

To this end, the authors investigated the problems currently facing manufacturing sites and identified their key factors. They then used these factors to formulate the Intellectual Working Value Improvement Model "IWV-IM" designed to improve worker dedication. More specifically, "working value" was defined from a 4M-E(Man, Machine, Method, Material and Environment) perspective by: 1) organizing the various factors underlying current issues using a matrix diagram, 2) using text mining while conducting a multivariate analysis, and 3) discovering and clarifying relationships among the identified factors. This analysis approach resulted in the identification of a group of three factors (work demands, psychological demands, and personal fulfillment) which were then used to formulate the different levels of the model. The effectiveness of the Intellectual Working Value Improvement Model was then verified at Toyota, a leading manufacturer.

\section{NECESSITY OF WORKING VALUE IMPROVEMENT}

\section{Current Situation of Worksites}

Until recently, companies worked to improve the efficiency of worksites through initiatives such as strict labor cutbacks and 5S (sorting, straightening, sweeping, standardizing, sustaining) measures. Further improvements were made to upgrade the quality of people's physical working environments from a health and ergonomic perspective, resulting in better worksite conditions for women and older workers. Still, it is difficult to get employees to see the value of their work. The percentage of temporary employees at Japanese manufacturing sites is increasing, and there is concern that the capacity of domestic worksites will be compromised as production operators inexperienced in manufacturing are trained in methods developed overseas. Under these conditions, getting workers 
to recognize the value of their work and gain proficiency in higher-level skills is an urgent task (Amasaka, et al., 2000: Amasaka, 2004: Sakai, et al., 2005).

\section{Meaning of Working Value Improvement}

The "working value" the authors have in mind here can be defined as "the performance and outcome of work" brought about by on-site workers, which contributes to customer value. That is to say, the improvement in working value involves the creation of value of the on-site work by the workers themselves who also share the "sense of purpose in life" through mutual enlightenment received from team activities, and thus experience self realization and self development. In other words, such workers can find significance in working for their companies and contribute to society by continuously offering products that meet customer expectations. The significance of studying working value improvement is the creation of intellectual work for each worker, which will be able to enhance their motivation and thus serve as a means of investment by the improved quality of products, eventually contributing to quality management. The authors therefore contend that improved labor productivity through positive changes in working values is a key to successful global production. In their research, the authors construct a model of working value that considers the value of the work itself and the working environment, rather than the usual concept of working value in terms of wages earned (Amasaka, 2003a: Yamaji, et al., 2007, 2008).

\section{CONSTRUCT THE INTELLECTUAL WORKING VALUE IMPROVEMENT MODEL "IWV-IM"}

In this section, the authors construct a working value improvement model "IWV-IM" that features different levels, each representing a key factor in the path to increasing working value. Applying this model at worksites is thought to improve the quality of products and contribute to better quality management. This is achieved by increasing the motivation of individual workers, so that they pay more attention to preventing defective products and then enact that mindset by working together as a team to implement quality improvement measures.

\section{Principle of Working Value Improvement}

Clearly, the performance of on-site workers who manufacture goods is critical to achieving high-quality products, quick development and global distribution. However, most managers focus on workers' skills and knack for the work, and rarely think about the environment in which the work is performed. The authors therefore propose this model as a way of grasping the value of the work that workers perform. Figure 1 shows the basic principles of working value. It consists of five levels, with the lower levels indicating more fundamental worker needs (Amasaka, 2003a, 2003b).

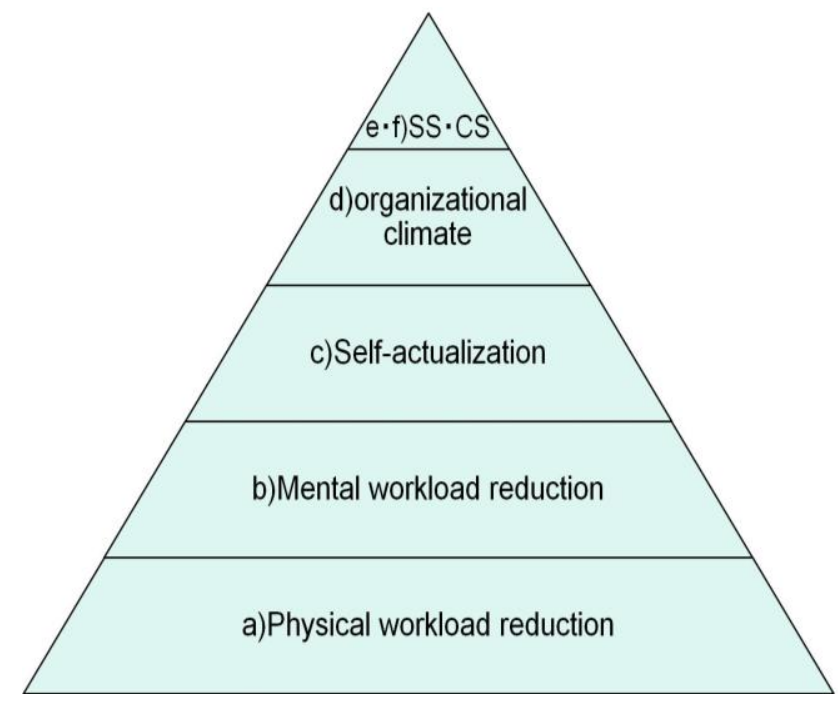

Figure 1: The principle of intellectual working value improvement model 
a) Physical workload reduction puts emphasis on the necessity of a practical program as well as implementation of the reduction of heavy labor work in continuous and tedious on-site operations with a view to realizing "error-free manufacturing" to meet customer expectations.

b) Mental workload reduction from the standpoint of securing process capability focuses on prioritizing the realization of a comfortable working environment in which the workers can fully demonstrate their skills.

c) Self-actualization, worker morale improves by learning higher technology and skills.

d) So workers contribute to an organization by utilizing those technologies and skills.

e) More workers contribute to social satisfaction and.

f) customer satisfaction by producing high quality products

Meeting these different needs will enable companies to achieve high-quality manufacturing and allow them to develop products that respond to customer preferences.

By using these skills and techniques to put products on the global market that meet customer needs, companies can d) respond to social needs and contribute to their organization, thereby e) contributing to society. Providing the high-quality products that customers seek f) leads to increased customer satisfaction. By achieving these tasks in a balanced way, it is expected that even more advanced tasks will present themselves. Repeating the process will thus result in ever-increasing levels of working value (Amasaka, 2007: Yamaji, et al., 2006a, 2006b).

\section{Proposal Intellectual Working Value Improvement Model}

This research delves deeper into the basic principles of working value improvement and offers a step-bystep process for achieving that improvement for all workers-male or female, young or old. The result is the Intelligent Working Value Improvement Model shown in Figure 2. The model shows the steps leading to working value improvement, each of which includes key factors. The balanced achievement of these different factors is what leads to working value improvement. The following sections outline the approach used to create the model (Tsunoi, 2009).

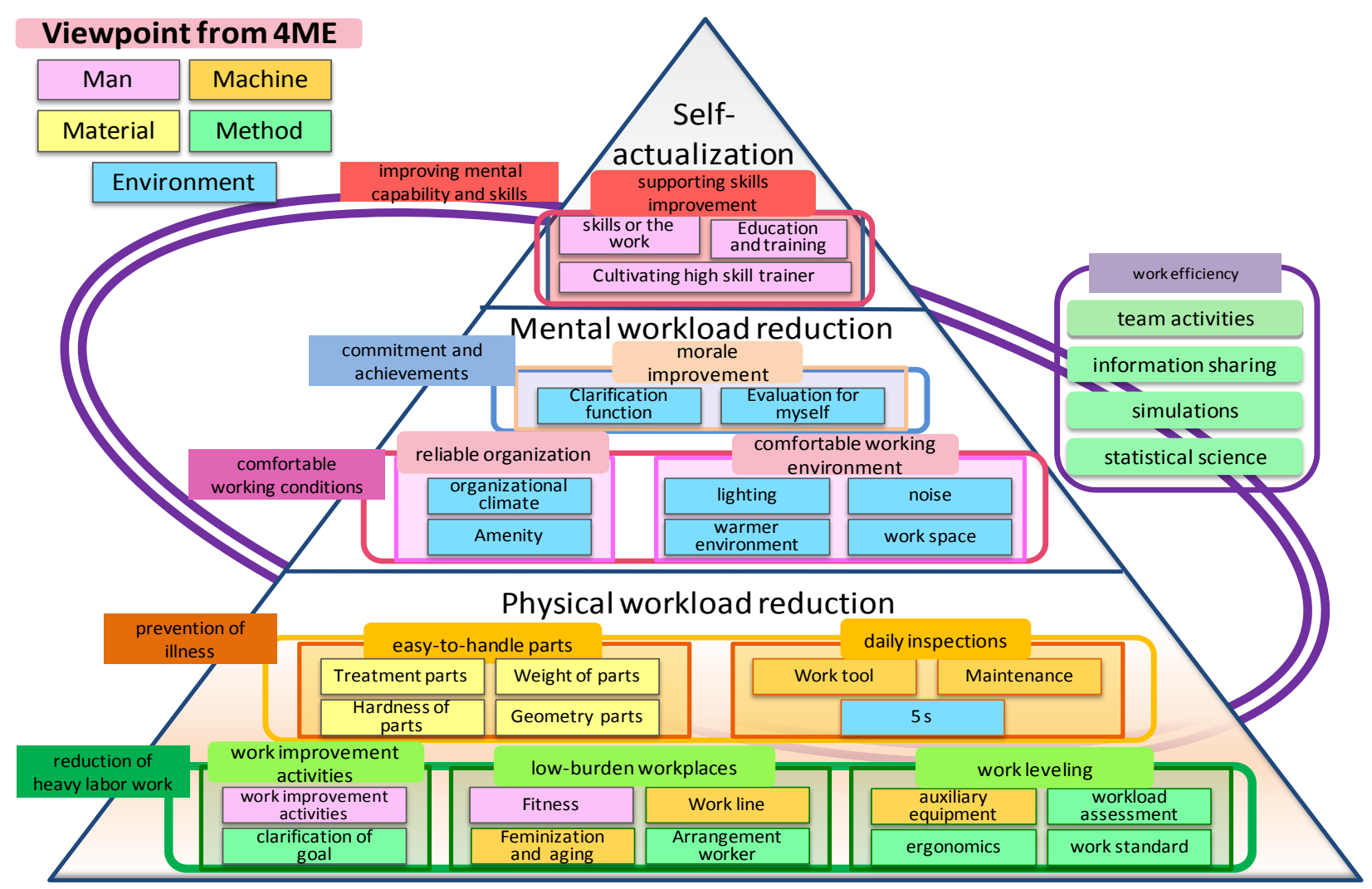

Figure 2: The Intellectual Working Value Improvement Model IWVIM 


\section{Approach for Study}

The process that led to the creation of the model can be represented in a pyramid chart. First, (i) a preliminary investigation was conducted and a framework was established. Next, (ii) working issues were identified from the 4M-E perspectives, and (iii) the various factors underlying those issues were organized using a matrix diagram. Text mining was conducted along with multivariate analysis to discover and clarify relationships among the identified factors. This analysis approach resulted in the identification of a group of three factors (work demands, psychological demands, and personal fulfillment), which were then (iv) used to formulate the different levels of the Intelligent Working Value Improvement Model. The effectiveness of the model was then verified at Toyota, a leading manufacturer.

\section{Identification Work Problems}

Delving deeply into the basic principles underlying working value improvement required grasping the kind of conditions that actually exist at worksites. To this end, the authors chose to look at the auto manufacturing industry, which has a high percentage of employees - many of whom work on production lines in the four most physically demanding processes: welding, coating, machine processing, and assembly. The authors met with these workers, toured the plants, and took video of actual scenes from the worksite to grasp actual conditions there. Having acquired knowledge of actual worksite conditions, issues were written on self-sticking notes and organized from two perspectives, with the purpose of structurally identifying problem areas at worksites. The two perspectives were 4M-E (man, machine, method, material, and environment) and working values (work demands, psychological demands, and personal fulfillment).

\section{Classification Work Problems}

In order to organize the characteristics of the problem areas identified in 3.3.1, these areas were classified along two axes (4M-E and working values) using a matrix diagram.

\section{Discovery of the Key Terms}

After classifying work problem areas along two axes in 3.3.2, the next challenge was finding key terms to describe each of the resulting strata. To do this, the authors used text mining along the 4M-E axis to discover the relationships among words, which resulted in the identification of 32 key terms.

\section{Discovery and Clarification the Relationships among the Key Terms}

In this section, the authors discovered and clarified the relationships among the key terms identified in 3.3.3. First, the 32 key terms and 250 problem areas were converted into binary data. A partial correlation analysis was then conducted using this binary data, and relationships to each key term were quantified. Highly correlated key terms were grouped together based on these numerical results, thus elucidating the relationships among work problem areas and leading to the creation of the factor association chart shown in Figure 3.

\section{Construction of the Working Value Improvement Model}

The chart in Figure 2, which shows the Intelligent Working Value Improvement Model as a series of working value improvement stages, was generated from the factor association chart for problem work areas. Like Maslow's hierarchy of needs, lower-tier items represent more fundamental worker needs. The different levels correspond to the groups classified through data analysis. The chart also indicates which 4M-E item the factors within each level correspond to. Finally, the "work efficiency" ring that encompasses some of the stages shows factors that are important in ensuring efficient implementation and improvement.

\section{VERIFICATION THE EFFECTIVENESS OF MODEL}

The authors verified the effectiveness of this model at Toyota, a leading manufacturer. Our verification is research case studies that apply to each stage of the model. It is through actual implementation at Toyota and the generation of results in these case studies that the effectiveness of the model was demonstrated. 


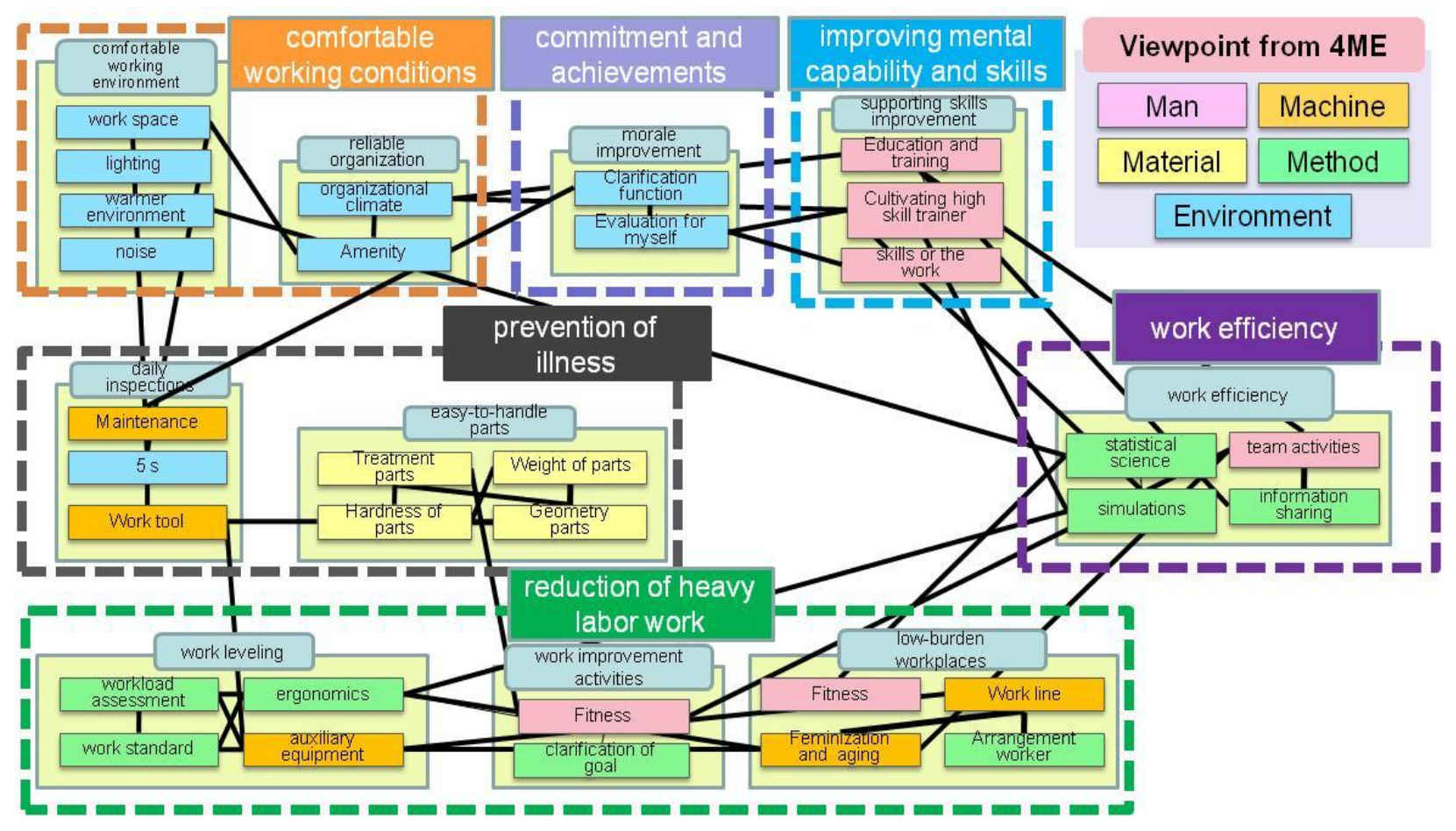

Figure 3: Factor Association Chart

\section{CONCLUSION}

Using a scientific approach, the above research grasped actual problem areas facing worksites from a 4ME and working values perspective. The Intelligent Working Values Improvement Model was created based on this information, outlining a step-by-step route to working values improvement. Applying this model at worksites can result in a transformation of skills and techniques leading to the continuing ability of companies to manufacture high-quality products.

\section{AUTHOR INFORMATION}

Masashi Tsunoi is a graduate student of the College of Science and Engineering at Aoyama Gakuin University.

Manabu Yamaji is a researcher in the Advanced Research Center for Human Sciences at Waseda University, Japan. He received his Master of Engineering degree in Graduate School of Information Systems at University of ElectroCommunications in 1999. His current research and teaching interests are in the general area of production engineering. In particular, he is interested in Total Quality Management, Computer Aided Engineering.

Kakuro Amasaka is a Professor in the College of Science and Engineering at Aoyama Gakuin University, Japan. $\mathrm{He}$ received his Ph.D. degree in Precision Mechanical and System Engineering, Statistics and Quality Control at Hiroshima University in 1997. His current research and teaching interests are in the general area of production engineering. In particular, he is interested in New JIT. He is a member of POMS and EurOMA.

\section{REFERENCES}

1. Amasaka, K., (2000), AWD6P/J Report of First Term Activity 1996-1999: Creation of 21st Century Production Line in Which People Over 60's Can Work Vigorously, Toyota Motor Corporation, pp.1-93. (in Japanese) 
2. Amasaka, K., (2003a), Development of Science TQM, A New Principle of Quality Management, International Journal of Production Research, Vol.42, No.17, pp.3691-3706.

3. Amasaka, K., (2003b), Proposal and Implementation of the "Science SQC" Quality Control Principle, International Journal of Mathematical and Computer Modeling, Vol.38, No.11-13, pp.1125-1136.

4. $\quad$ Amasaka, K., (2004), keynote Lecture past, present, future of industrial management, The Japan Society for Production Management Journal, No.20, pp.1-8.

5. Amasaka, K., (2007), New Japan Production Model, An Advanced Production Management Principle - Key To Strategic Implementation Of New JIT, Journal of Business \& Economics Research, Vol. 6, No. 7, pp.6780 .

6. Sakai, H., Amasaka, K., (2005), Strategic HI-POS, Intelligence Production Operating System: Applying Advanced TPS to Toyota's Global Production Strategy -, WSEAS Transactions on Advances in Engineering Education, Vol.3, Issue3, pp.223-230.

7. Yamaji, M., Sakai, H., Amasaka, K., (2006a) Intellectual Working Value Improvement Model Utilizing Advanced TPS: Applying New JIT, Toyota's Global Production Strategy, Proceedings of the International Applied Business Research Conference, Cancun, Mexico, pp.1-10 (CD-ROM).

8. Yamaji, M., Sakai, H., Amasaka, K., (2006b) Proposal working value model for manufacturing, The Japan Society for Production Management Journal, No.23, pp.73-76.

9. Yamaji, M., Amasaka, K.,(2007), Evolution Of Technology And Skills In Production Workplaces Utilizing Advanced TPS, Journal of Business \& Economics Research, Vol. 5, No. 6, pp.61-66.

10. Yamaji, M., Amasaka, K., (2008), New Japan Quality Management Model: Implementation of New JIT for Strategic Management Technology, Journal of Business \& Economics Research, Vol. 7, No. 3, pp.107-114.

11. Tsunoi, M., (2009), Research for Building an Intellectual Working Value Improvement Model, School of Science and Engineering, Aoyama Gakuin University, Graduation Thesis, pp.1-71. 